\title{
$\mathrm{O}_{2} / \mathrm{Ar}$ 플라즈마를 이용한 구리호일 표면 개질에 관한 연구
}

\author{
이종찬 ${ }^{1}$, 손진영 ${ }^{1}$, 김문근 ${ }^{1}$, 권광호 $^{1}$, 이현우 $^{2, a}$ \\ 1 고려대학교 제어계측공학과 \\ 2 한서대학교 전자컴퓨터통신공학부
}

\section{A Study on the Surface Modification Mechanism of Copper Foil Using $\mathrm{O}_{2} /$ Ar Plasma}

\author{
Jongchan Lee ${ }^{1}$, Jinyoung Son ${ }^{1}$, Moonkeun Kim ${ }^{1}$, Kwang-Ho Kwon ${ }^{1}$, and Hyunwoo Lee ${ }^{2, a}$ \\ ${ }^{1}$ Department of Control and Instrumentation, Korea University, Sejong 339-700, Korea \\ 2 Division of Electronic, Computer and Communication Engineering, Hanseo University,
} Seosan 356-706, Korea

(Received September 6, 2013; Revised October 4, 2013; Accepted October 14, 2013)

\begin{abstract}
In this study, the surface modification of copper foil using an inductively coupled $\mathrm{O}_{2} / \mathrm{Ar}$ plasma as $\mathrm{O}_{2}$ gas fraction $(0 \sim 100 \%)$ was investigated in order to improve the surface characteristics. After plasma treatment, the measurement of the surface roughness, surface contact angle and surface energy were performed for the surface analysis of copper foil. As a result, the surface roughness and the surface energy were increased. And plasma diagnostics was performed by a double Langmuir probe (DLP) and optical emission spectroscopy (OES). Using these results, the plasma surface modification mechanism was investigated.
\end{abstract}

Keywords: Copper foil, Roughness, Surface energy, Plasma, $\mathrm{O}_{2}, \mathrm{Ar}$, DLP, OES

\section{1. 서 론}

구리호일은 우수한 전도성을 가지고 있어 프린트 회로 기판 (printed circuit board, $\mathrm{PCB}$ )상의 도체와 리튬이차전지 극판의 집전체로 사용되고 있다 [1,2]. 또한 최근 전자기기의 소형화와 차세대 기기인 플렉 서블 전지 및 디스플레이 개발로 인해 구리호일의 접 착력 향상을 위한 연구가 요구되고 있다. 구리호일의

a. Corresponding author; hwlee@hanseo.ac.kr

Copyright (C2013 KIEEME. All rights reserved.

This is an Open-Access article distributed under the terms of the Creative Commons Attribution Non-Commercial License (http://creativecommons.org/licenses/by-nc/3.0) which permits unrestricted non-commercial use, distribution, and reproduction in any medium, provided the original work is properly cited.
접착력 증가는 프린트 회로 기판 $(\mathrm{PCB})$ 의 안전성을 증가시킬 수 있으며 리튬이차전지에서 구리호일의 표 면적과 접착력의 증가는 전지의 안전성뿐만 아니라 활물질에서 생성된 전자를 더 잘 수집할 수 있게 해 주어 전지 성능도 향상된다 [3]. 또한 구부리거나 휘 어지는 플렉서블 기기에서 계면간의 접착력은 중요한 문제이다.

구리호일의 접착력 증가 및 표면 특성 향상을 위한 방법으로 표면개질기술이 이용되고 있다. 여러 표면 개질 기술로 증착, 도금, 열처리, 플라즈마처리 등의 방법으로 이루어지고 있다. 그 중 하나인 플라즈마 표면처리기술은 물리적, 화학적 반응이 물질의 전체 적인 성질을 변화시키지 않고 표면층에 국한되어 균 
일하게 일어나므로 표면을 안정하게 다룰 수 있으며 저온에서 안정한 물질을 처리 할 수 있는 장점을 지 니고 있다 [4,5].

그러나 플라즈마 처리를 통한 구리 호일의 표면 개 질에 대한 연구는 부족한 상태이며 이에 대한 메커니 즘을 규명한 논문은 아직 발표되지 않고 있다. 따라 서 구리 호일 표면을 $\mathrm{O}_{2} / \mathrm{Ar}$ 플라즈마 처리한 후에 표면의 거칠기 변화를 분석하기위해, 플라즈마 처리 조건에 따른 박막 표면 변형을 원자력 현미경 (atomic force microscopy, AFM)을 이용하여 조사하 였다. 또한 접촉각 측정 장비를 이용하여 표면에너지 를 분석하였다. 구리 호일 표면개질 메커니즘을 연구 하기 위해 플라즈마 진단을 이중 랭뮤어 탐침 (double Langmuir probe, DLP) 및 광학적 방출 특성 분석 (optical emission spectroscopy, OES)을 이용하 여 수행하였다. 이와 같이 표면 개질 특성과 플라즈 마 특성과의 상관관계를 분석하고 메커니즘을 규명하 고자 하였다.

\section{2. 실험 방법}

본 연구에서 사용한 플라즈마 표면처리 장비는 고 진공에서 고밀도 플라즈마를 형성하는 유도 결합 플 라즈마 (inductively coupled plasma) 장비를 사용하 였다. 플라즈마 내에 유입되는 가스 조성은 $\mathrm{O}_{2} / \mathrm{Ar}$ 가스이다. 총 유량은 $40 \mathrm{sccm}$ 으로 고정하였으며, $\mathrm{O}_{2}$ 가스 비율을 $0 \%$ 에서 $100 \%$ 까지 변화하여 조사하였다. 기타 공정 조건은 소스 파워 $50 \mathrm{~W}$, 공정압력 6 mTorr, 공정 시간은 30 초이다. 실험에 사용된 구리호 일은 두께 $18 \mu \mathrm{m}$ 의 압연동박을 사용하였다. 처리 후 표면개질에 의한 표면거칠기를 분석하기 위하여 원자 력 현미경 (atomic force microscope, AFM)을 이용 하였다. 또한 구리호일의 표면에너지를 측정하기 위 해 친수성인 DI water와 소수성인 Diiodomethane을 각 $10 \mu$ 의 양만큼 떨어뜨린 후 접촉각 측정 장비를 이용하여 접촉각을 측정하였다. 모든 접촉각 측정 실 험은 3 회 반복 측정하여 평균값과 편차를 구하였다. 측정된 접촉각을 이용해서 Owens \& Wendt 방법을 사용하여 표면에너지를 계산하였다 [6].

구리호일 표면 개질의 메커니즘을 도출하기 위하여 (double Langmuir probe, DLP) (DLP 2000, Plasmart Inc.)를 사용하여 이온 전류 밀도를 조사하였고 플라 즈마 내의 화학종들의 특성을 조사하기 위해 (optical emission spectroscopy, OES) (FC - UV600 - 2 JiNYOUNG Inc.) 분석을 하였다.

\section{3. 결과 및 고찰}

그림 1 은 플라즈마 처리를 통한 표면 거칠기의 변 화를 살펴보기 위하여 플라즈마 처리 전·후의 표면을 $\mathrm{AFM}$ 을 이용하여 관찰한 것이다. 그림 $1(\mathrm{a})$ 는 플라즈 마 처리 전의 구리호일의 이미지이고, 그림 $1(\mathrm{~b})$ 는 $\operatorname{Ar} 100 \%$ 조건에서 플라즈마 처리 후의 이미지이다. 구리호일은 플라즈마 표면처리에 의해 표면이 전반적 으로 거칠기가 증가했음을 보여주고 있다.

(a)

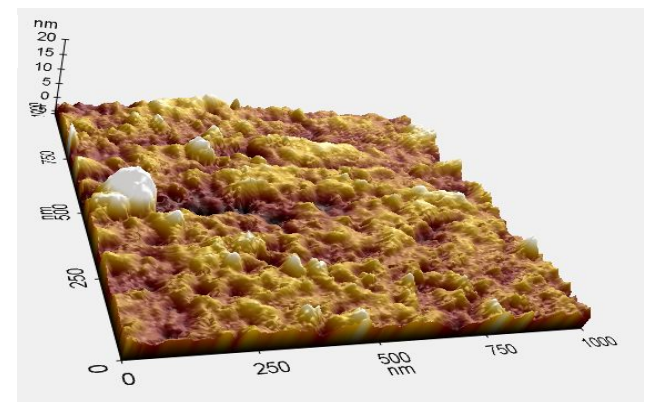

(b)

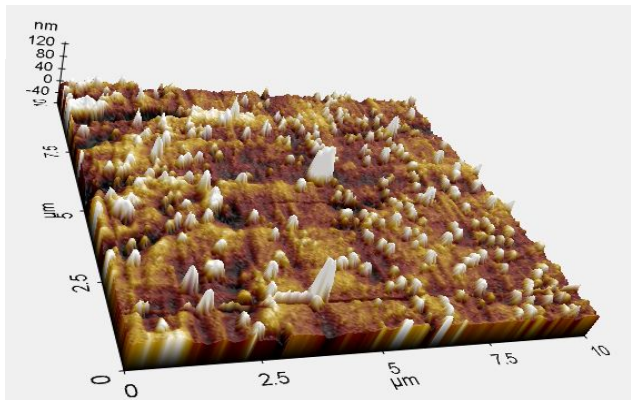

Fig. 1. AFM images for (a) Ref. copper foil and (b) after plasma treatment copper foil surface.

이러한 $\mathrm{O}_{2} / \mathrm{Ar}$ 플라즈마 처리에 의해 증가한 표 면거칠기를 수치적으로 표현한 것을 그림 2에 나타내 었다. $\mathrm{AFM}$ 으로 측정한 표면 거칠기는 $\mathrm{RMS}$ 값을 사 용하여 계산하였다. 플라즈마 처리 전의 표면거칠기 는 $1.54 \mathrm{~nm}$ 이며 플라즈마 처리 후에는 $\mathrm{O}_{2}$ 가스 비율 $0 \%$ 조건에서는 $13.06 \mathrm{~nm}$ 이다. $\mathrm{O}_{2}$ 가스 비율이 증가 하면서 점차 감소하여 $\mathrm{O}_{2}$ 가스 비율 $100 \%$ 조건에서 는 $9.79 \mathrm{~nm}$ 까지 감소하지만 표면처리 전과 후에 표면 


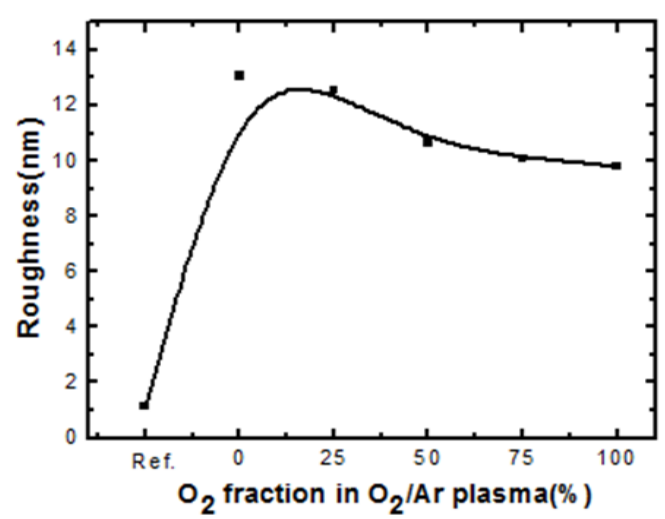

Fig. 2. Surface roughness change of copper foil as a function of $\mathrm{O}_{2}$ fraction in $\mathrm{O}_{2} /$ Ar plasma.

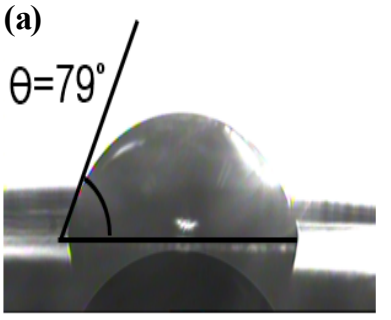

$\langle$ Ref. $\rangle$ (b)

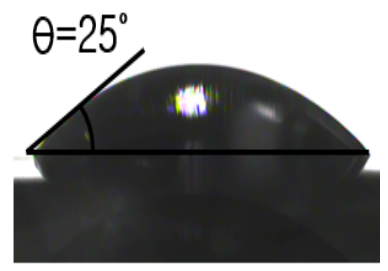

$\left\langle\mathrm{O}_{2} / \mathrm{Ar}=10 / 30\right\rangle$
Fig. 3. (a) Contact angle of Ref copper foil, (b) contact angle of copper foil after plasma treatment.

거칠기는 5 7배 이상의 큰 증가를 보였다. $\mathrm{O}_{2}$ 가스 비율의 증가에 따라 표면거칠기가 감소한다는 것은, 즉 $\mathrm{Ar}$ 가스 비율의 감소에 따라 표면거칠기가 증가 한다는 것이다. 이는 $\mathrm{Ar}$ 가스에 증가에 따라 이온 충 돌 현상이 증가하여 거칠기가 증가한 것으로 사료되 며 다음 결과들로 이를 확인할 수 있다.

그림 3 은 플라즈마 처리 전·후의 구리호일 표면과 D.I water의 접촉각을 확인하기 위하여 접촉각 측정 장비를 사용한 이미지이다. 플라즈마 처리 전의 접촉 각은 $79^{\circ}$ 이고, 플라즈마 처리 후의 접촉각은 $25^{\circ}$ 로 매 우 낮아진 것을 확인할 수 있다. 구리 표면이 플라즈 마 표면 처리에 의해 친수성으로 변하여 접촉각이 작 아지고 표면에너지가 증가함을 확인할 수 있다 [7]. 플라즈마 표면 처리 후 증가한 표면에너지는 Owens $\&$ Wendt 방법에 따라 다음의 식을 사용하여 구리호 일과의 polar force와 dispersion force를 확인하였다.

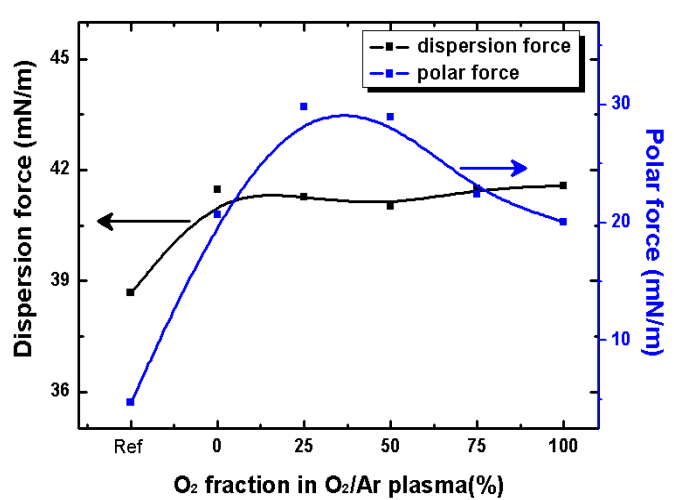

Fig. 4. Polar and dispersion force of $\mathrm{O}_{2}$ fraction in $\mathrm{O}_{2} /$ Ar plasma.

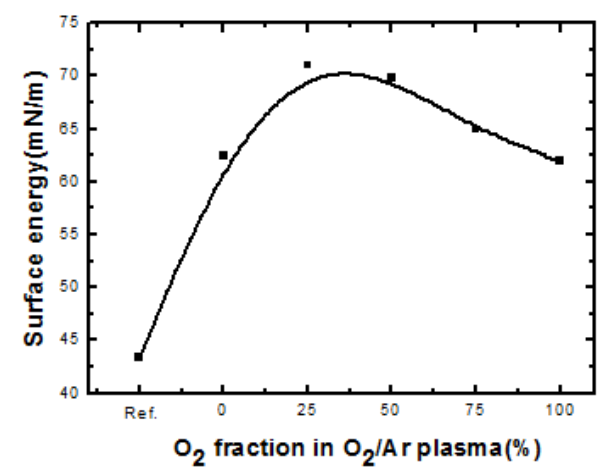

Fig. 5. Surface energy of $\mathrm{O}_{2}$ fraction in $\mathrm{O}_{2} / \mathrm{Ar}$ plasma.

$$
\gamma_{L V} \times(1+\cos \theta)=2\left(\gamma_{S}^{d} \gamma_{L}^{d}\right)^{\frac{1}{2}}+2\left(\gamma_{S}^{p} \gamma_{L}^{p}\right)^{\frac{1}{2}}
$$

위의 식을 통해 각 조건에 따른 polar force $\left(\gamma_{L}^{p}\right)$ 와 dispersion force $\left(\gamma_{L}^{d}\right)$ 의 그래프를 그림 4 에 나타내었 으며 두 값을 더한 표면에너지를 그림 5에 나타내었 다. 그림 4에서 처리 전의 polar force와 dispersion force는 각 $4.72 \mathrm{mN} / \mathrm{m}$ 과 $38.67 \mathrm{mN} / \mathrm{m}$ 로 처리 후와 큰 차이를 보인다. 처리 후의 polar force는 증가하다 감소하며 그림 5의 표면에너지와 유사한 경향을 보인 다. 처리 후의 dispersion force는 약 $41 \mathrm{mN} / \mathrm{m}$ 의 값 에서 큰 변화가 없는 것을 확인할 수 있다. Polar force의 변화가 표면에너지의 변화의 주요 요인이라 고 할 수 있다. 이것은 $\mathrm{O}_{2} / \mathrm{Ar}$ 플라즈마 처리에 의해 구리호일 표면에 $\mathrm{O}$ 를 포함한 $\mathrm{CuO}, \mathrm{Cu}_{2} \mathrm{O}$ 와 같은 functional group이 생성되어 이에 따른 polar force의 변화에 따라 표면에너지가 변화한 것이라 사료된다 [8]. 


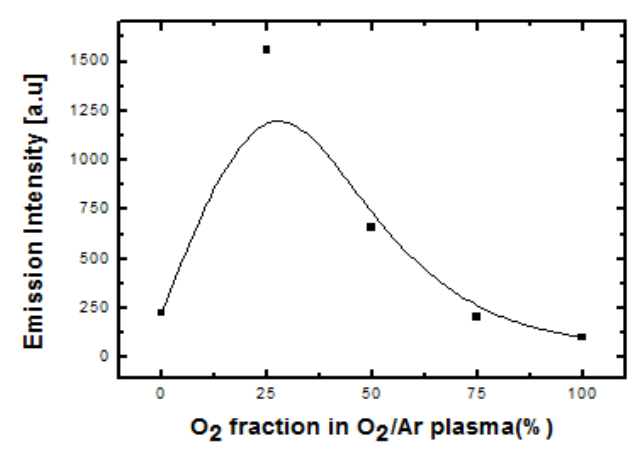

Fig. 6. OES emission intensity of $\mathrm{O}_{2}$ fraction in $\mathrm{O}_{2} / \mathrm{Ar}$ plasma.

표면 개질에 의해 증가한 표면거칠기와 표면에너지 는 플라즈마와 밀접한 관련이 있는 것으로 판단되어 이러한 표면 개질 메커니즘을 확인하고자 플라즈마 진단을 수행하였다. 플라즈마 진단을 위해 먼저 플라 즈마 처리 중 $\mathrm{O}_{2}$ 의 화학적 반응의 정도를 알아보았 다.

그림 6 은 $\mathrm{O}_{2}$ 가스 혼합비 변화에 따른 플라즈마 내 에 형성되는 $\mathrm{O}$ 라디칼 $[777 \mathrm{~nm}]$ 의 방출 광세기의 변 화를 나타낸 것이다. 그림에 나타난 바와 같이 $\mathrm{O}$ 라 디칼의 강도는 혼합가스에서 $\mathrm{O}_{2}$ 가스의 비율이 $25 \%$ 일 때 최대이다. 이 조건에서 $\mathrm{O}$ 라디칼의 광 방출세 기가 최대이므로 화학적 반응의 정도가 최대인 것이 라고 추론할 수 있다. 또한 표면에너지와 유사한 경 향을 보이는 것으로 보아 $\mathrm{O}$ 라디칼의 강도에 따라 표면에너지도 증가하는 것을 알 수 있다.

또한 DLP를 이용하여 플라즈마 내의 물리적 상태 를 분석하였다. 그림 7 과 8 은 플라즈마 내의 $\mathrm{O}_{2}$ 가스 비율에 따른 플라즈마 내 이온 밀도와 이온전류밀도 를 나타낸 것이다. 플라즈마 밀도 $(\mathrm{Np})$ 와 이온전류밀 도 (Jis)는 플라즈마 내에 형성되는 이온의 농도를 의 미한다. 또한 $\mathrm{Ar}$ 이온의 경우는 life time이 길어서 이온의 충돌의 확률은 커지고 따라서 페닝 이온화 (penning effect)확률이 커진다 [9]. 따라서 $\mathrm{Ar}$ 이온의 증가에 따른 $\mathrm{Np}$ 의 증가는 플라즈마 내 이온 농도의 증가를 의미하며 구리호일 표면에 도달하는 선속 (flux)이 증가하여 충돌하는 이온의 양 또한 증가한다 [10]. 따라서 그림 2에서 $\mathrm{Ar}$ 의 비율 증가에 따라 표면 거칠기가 증가한 것은 $\mathrm{Ar}$ 비율에 따라 이온 충돌 현 상이 더 증가했기 때문이라 사료된다.

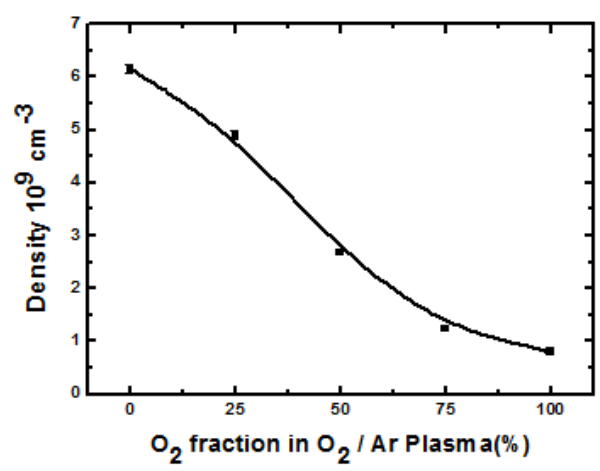

Fig. 7. Positive ion density of the plasma measured by double Langmuir probe as a function of gas ratio of $\mathrm{O}_{2}$

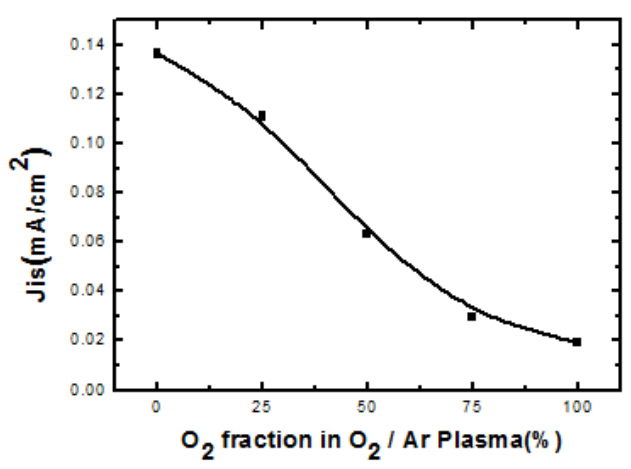

Fig. 8. Ion current density of the plasma measured by double Langmuir probe as a function of gas ratio of $\mathrm{O}_{2}$.

\section{4. 결 론}

본 연구는 플라즈마 처리를 통해 구리호일의 표면 개질을 수행하였다. $\mathrm{O}_{2} / \mathrm{Ar}$ 플라즈마의 가스 혼합 비율을 조절하며 구리호일의 거칠기와 표면에너지의 변화를 관찰하였다. $\mathrm{AFM}$ 을 이용하여 표면 거칠기를 확인하였고, Owens \& Wendt의 방법을 이용하여 접 촉각을 측정하여 표면에너지를 구했다. 표면처리 후 구리호일의 표면 거칠기와 표면에너지가 증가했음을 확인하였다. 공정 조건에 따른 플라즈마 특성을 $\mathrm{DLP}$ 와 $\mathrm{OES}$ 를 이용하여 분석하였고 이에 따른 표면특성 과의 상관관계를 고찰하였다. $\mathrm{Ar}$ 가스 증가에 따라 표면거칠기가 증가하였고 $\mathrm{DLP}$ 분석을 통해 $\mathrm{Ar}$ 가스 에 의한 이온충돌이 원인이 되는 것을 확인하였으며 표면에너지는 $\mathrm{O}$ 라디칼과 유사한 경향을 보여 $\mathrm{O}$ 에 의한 화학적 반응이 영향을 미치는 것을 확인하였다. 


\section{REFERENCES}

[1] X. Ye, M. De Bonte, J. P. Celis, and J. R. Roos, J. Electrochem. Soc., 139, 1592 (1992).

[2] J. W. Braithwaite, G. Angelo, N. Ganesan, and J. L. Samuel. J. Electrochem Soc., 146, 448 (1999).

[3] N. Tamura, R. Ohshita, M. Fujimoto, M. Kamino, and S. Fujitani, J. Electrochem. Soc., 150, A679 (2003).

[4] E. T. Kang, K. L. Tan, K. Kato, Y. Uyama, and Y. Ikada, J. Macromolecules, 29, 6872 (1996).

[5] J. R. Chen and T. Wakida, J. Appl. Polym. Sci. 63,
1733 (1997).

[6] D. K. Owens and R. C. Wendt, J. Appl. Polym. Sci., 13, 1741 (1969)

[7] B. K. Kim, K. S. Kim, C. E. Park, and C. M. Ryu, J. Adhesion Sci. Technol., 16, 509 (2002).

[8] S. J Cho, J. W Choi, and I. S Bae, J. Appl Phys., 50, 01AK02 (2011).

[9] C. R. Aita, J. Vac. Sci. Technol., A3, 625 (1985).

[10] K. H. Kwon, A. Efremov, M. Kim, N. K. Min, J. Jeong, M. Hong, and K. Kim, J. Vac. Sci. Technol., A28, 226 (2010). 